\title{
Mikrodalga Görüntüleme Sistemleri için Mikroşerit Anten Tasarımı
}

\author{
Mustafa Mutlu' ${ }^{1}$, Çetin Kurnaz ${ }^{2 *}$ \\ 1 Ordu Üniversitesi, Teknik Bilimler MYO, Ordu, Türkiye (ORCID: 0000-0001-6756-0668) \\ 2 Ondokuz Mayıs Üniversitesi, Mühendislik Fakültesi, Elektrik-Elektronik Mühendisliği Bölümü, Samsun, Türkiye (ORCID: 0000-0003-3436-899X)
}

(International Symposium on Multidisciplinary Studies and Innovative Technologies (ISMSIT) 2020 - 22-24 Ekim 2020)

(DOI: 10.31590/ejosat.819567)

ATIF/REFERENCE: Mutlu, M. \& Kurnaz, Ç. (2020). Mikrodalga Görüntüleme Sistemleri için Mikroşerit Anten Tasarımı. Avrupa Bilim ve Teknoloji Dergisi, (Özel Sayı), 129-137.

\section{$\ddot{O} \mathbf{z}$}

Bu çalışmada, pek çok kanser tümörünün tespitinde kullanılmak üzere giyilebilir bir dikdörtgen mikroşerit anten tasarımı ve gerçeklemesi yapılmıştır. Mikrodalga görüntüleme sistemlerinde hem alıı hem de verici olarak kullanılabilecek antenin yama ve toprak kısmı iletken (bakır) banttan, yalıtkan kısmı ise PF-4 (köpük) malzemeden oluşturulmuştur. CST programı kullanılarak tasarlanan antenin çalışma frekans aralı̆̆ $1.71 \mathrm{GHz}$ ile $8.53 \mathrm{GHz}$ arasında olup band genişliği $6.82 \mathrm{GHz}$ 'dir. Gerçeklenen antenin bant genişliği ise $6.75 \mathrm{GHz}$ 'dir (1.6 GHz- $8.35 \mathrm{GHz})$. Anten kazanc1 $5.31 \mathrm{~dB}$ gibi oldukça yüksek bir değerdir. Dar bantlı ve düşük kazançlı klasik mikroşerit antenlerden farklı olarak tasarlanan ve gerçeklenen anten ultra geniş bant gerektiren uygulamalarda rahatlıkla kullanılabilir. Ayrıca tasarlanan antenin ışıma karakteristiğinin oldukça iyi ve etrafinda oluşan elektrik alan değişiminin sağlık açısından bir sorun yaratmayacak düzeyde olduğu da söylenebilir. İnsan vücudundaki organların iletkenlik değerlerinin değiş̧iminin $1 \mathrm{GHz}-10 \mathrm{GHz}$ frekans bandında yüksek olduğu; sağlam dokular ile tümörlü/kanserli dokuların iletkenlik değerlerinin farklı olduğu gerçeğinden yola çıkarak tasarlanan antenin akciğer, beyin, karaciğer, böbrek gibi organlarda bulunan tümörleri tespit etme için dizayn edilecek mikrodalga görüntüleme sistemlerinde kullanılabilir. Ayrıca tasarlanan antenin giyilebilir bir formda olması özellikle kanser riski yüksek olan hastaların sürekli izlemesine de olanak tanımaktadır.

\section{Microstrip Antenna Design for Microwave Imaging Systems}

\begin{abstract}
In this study, design and fabrication of a rectangular microstrip antenna is made to use for the determination of many cancer tumors. The antenna can be used as both receiver and transmitter, and its patch and ground part is composed of conductor (copper) band whereas the insulator part is made of PF-4 (foam). The antenna is designed by using the computer program CST, and its operation frequency interval is between $1.71 \mathrm{GHz}$ and $8.53 \mathrm{GHz}$, i.e, bandwidth is $6.82 \mathrm{GHz}$. Bandwidth of the fabricated antenna is $6.75 \mathrm{GHz}$ $(1.6 \mathrm{GHz}-8.35 \mathrm{GHz})$. Antenna gain is $5.31 \mathrm{~dB}$ which is quite high. The antenna which is designed and fabricated in a different way from the conventional narrowband and low-power microstrip antennas can be used easily in the cases requiring ultra high band. Besides, it can be said that propagation characteristics of the designed antenna is quite good, and the electric field variation aroud it is on the level that does not pose a problem for the health. Conductivity value variations of human organs between $1 \mathrm{GHz}-10 \mathrm{GHz}$ frequency band is high. Conductivity values of healthy tissues and tissues with tumor/cancer are different. By using these facts, the designed antenna can be used for microwave monitoring systems to be designed for determining the tumors in the organs such as lung, brain, liver and kidney. Also, since the designed antenna is wearable, it enables following the patients especially with high cancer risk continuously.
\end{abstract}

\footnotetext{
${ }^{*}$ Sorumlu Yazar: Ondokuz Mayıs Üniversitesi, Mühendislik Fakültesi, Elektrik-Elektronik Mühendisliği Bölümü, Samsun, Türkiye, ORCID: 0000-0003-3436-899X, ckurnaz@omu.edu.tr
} 
Avrupa Bilim ve Teknoloji Dergisi

Keywords: Microstrip Antenna, Wearable antenna, Ultra wideband, Microwave imaging, CST.

\section{Giriş}

Kanser tüm dünyada ciddi bir halk sağlığı problemi olup sebebi bilinen ölümler arasında kalp ve damar hastalıklarından sonra ikinci sırada yer almaktadır (WHO, 2020). Dünya sağlık örgütünün (world health organization, WHO) 2018 yılı verilerine göre toplam dünya nüfusunun içindeki toplam kanser vaka sayısı \%0.23'dür. Bu vakalardaki ölüm oranı \%52.8 ve bu ölümlerin \%11.6'sı ise akciğer kanseri kaynaklıdır (WHO, 2020; WCRF, 2020). Dünya genelinde ölüm nedeni en çok olan kanser türü akciğer kanseri olup, akciğer kanserinin erkeklerde görülmek sıklılığ 1 \%25'dir (WCRF, 2020). Sağlık Bakanlığı verilerine göre Türkiye'de kanserden ölüm oranın yaklaşık \%20 olup her y1l 80 bin kişi kanser nedeniyle hayatını kaybetmektedir (GCO, 2020; HSGM, 2020). Kanser tedavisinde erken tanı hayatta kalım için hayati öneme sahiptir. Kanserin erken tespiti için hâlihazırda değişik yöntemler kullanılmaktadır. Bunlar kısaca tıbbi görüntüleme ve kan testleri olmak üzere iki başlık altında toplanabilir. Tıbbi görüntüleme yöntemleri (röntgen, bilgisayarlı tomografi, manyetik rezonans görüntüleme ve PET) bir kişinin vücudunda kanserli hücrenin olup olmadığının belirlenmesinde günümüzde yaygın olarak kullanılmaktadır. Röntgen (X-1şını) ucuz ve basit bir görüntüleme tekniği olmasına rağmen, iyonlaştırıcı özelliğinden dolayı vücut için zarar oluşturabilmektedir. X ışını kemikten geçemediği için kemiklerin altında kalan bölgelerle ilgili bilgi alınamaz. Ayrıca röntgen üç boyutlu bilgi de içermemektedir. Bilgisayarlı tomografi (computer tomography, CT) yüksek çözünürlükte üç boyutlu veri ve anatomik bilgi verebilmektedir. Röntgene göre yüksek dozda radyasyon içerir. Yumuşak dokularda iyi veya kötü huylu olup olmadığıyla ilgili yanılma payına sahiptir. Manyetik rezonans görüntüleme (magnetic resonance imaging, MRI) temelde insan vücudundaki su molekülündeki hidrojen atomunu yönlendirme ve elektromanyetik enerji verip alarak üç boyutlu görüntüleme sağlamaktadır. Yumuşak dokularda çok iyi görüntüleme sağlamaktadır. MRI hem çok pahalı hem de diğer görüntüleme cihazlarına göre yavaştır. MRI'nın en büyük avantajı X ışını içermemesidir. Ultrason insan kulağının duyamayacağı frekansta ses dalgasına dayalı bir görüntüleme tekniği olup gerçek zamanlı düşük çözünürlükte görüntüleme sağlamaktadır. Ucuz ve sağlık açısından tehlike oluşturmaz, kısıtlı alanlarda (anne karnındaki çocuğun görüntülenmesi vb.) kullanılmaktadır. Nükleer görüntüleme (pozitron emisyon tomography, PET) insan vücuduna damar yoluyla radyoaktif madde vererek kanser tanısında ve tedavisinin (metastazda) takip edilmesi için üç boyutlu görüntüleme sağlamaktadır.

İnsan vücudundaki kanser tümörünü/hücresini mikrodalga görüntüleme (microwave imaging) tekniklerini kullanarak tespit etmek son yılların popüler çalışma konuları arasındadır. Mikrodalga görüntüleme tekniklerinin temel elemanı mikroşerit antenler olup, mikroşerit anten teknolojisindeki gelişmeler mikrodalga görüntüleme tekniklerine olan ilgiyi daha da artırmıştır. İlk mikroşerit anten 1953 yılında ABD'de Deschamps tarafından tasarlanmıştır (Deschamps, 1953). 1955 yılında Gutton ve Baissinot, Fransa'da UHF bölgesinde kullanılabilen düz bir mikroşerit antenin patentini almıştır (Georges ve Henri, 1955). İlk pratik mikroşerit anten 1974 yılında Munson tarafından yapılmıştır (Munson, 1974). Temel olarak dikdörtgen ve dairesel mikroşerit antenlerin tasarımı 1975 yılında Howell tarafından yapılmıştır (Howel, 1975). 1990 yılından sonra ise mikroşerit antenler biyomedikal uygulamalarda kullanılmaya başlanmıştır. Bu tarihten itibaren mikroşerit antenlerin biyomedikal alanda kullanımları her geçen gün artmıştır. Bu çalışmalardan özellikle ultra geniş bantlı (ultra wide band, UWB) biyomedikal uygulamalı olanlarından bazıları kısaca şu şekildedir. Kol üzerine yerleştirilebilen ve 3- $6 \mathrm{GHz}$ frekans bandı arasında çalışan giyilebilir mikroşerit anten dizayn edilmiştir (Zasowski ve dig., 2003). 3.1 GHz- 10.6 GHz frekansında çalışan giyilebilir bir UWB antenin dizaynını ve Voxel vücut modeli üzerinde, özgül emilim oranı (specific absorption rate, SAR) analizi yapılmıştır (Chahat ve dig., 2010). Dielektrik malzeme olarak pamuk polyesterden yapılmış ölçüleri aynı, dielektrik katsayıları farklı $2.45 \mathrm{GHz}$ frekansında çalışan giyilebilir dört tane dikdörtgen antenin bükülme koşulları altında incelenmesi yapılmıştır (Sankaralingam ve Gupta, 2010). Giyilebilir antenlerin sonlu entegrasyon yöntemi (Finite Integration Technique, FIT) kullanılarak SAR ve ortamla temasın biyolojik etkilerinin değerlendirilmesini yapmak için 4$11 \mathrm{GHz}$ arasında çalışan üçgen mikroşerit anten tasarlanmıştır (Tuovinen ve dig., 2013). İnsan vücut yüzeyine uyumlu geniş bantlı (2.4 GHz-12.8 GHz) eliptik anten tasarlamıştır (Faria, 2015). Hastane acil durumlarına ihtiyaç duyulduğunda izleme, uyarı verme yeteneğine sahip çok geniş bantlı (2-19 GHz) tekstil gibi giyilebilir dairesel mikroşerit anten tasarlanmıştır (Singh ve dig., 2015). Kablosuz vücut alan ağlı (wireless body area network, WBAN), UWB (3.1 GHz- 10.6GHz) bandında çalıșan, yamuk şekilli, kauçuk dielektrik malzemeli mikroşerit anten tasarımı ve analizleri yapılmıştır (Lakshmanan ve Sukumaran, 2015). HFSS (high frequency structure simulator) kullanılarak $1.43 \mathrm{GHz}-6.5 \mathrm{GHz}$ frekansında çalışan iki dikdörtgen giyilebilir anten tasarımı yapılmıştır (Akalya ve Nandalal, 2017). Giyilebilir uygulamalar için eşit yama alanına sahip ve üç farklı (kot, kadife, keçe) dielektrik tekstil kumaş kullanılarak $2.4 \mathrm{GHz}, 3 \mathrm{GHz}$ ve $5.8 \mathrm{GHz}$ frekansında çalışan, dikdörtgen, daire ve eşkenar üçgen şekilli giyilebilir üç antenin performansı incelenmiştir (Albairaqdar, 2018). Biyomedikal uygulamalar için $3 \mathrm{GHz}-12 \mathrm{GHz}$ frekans bandında çalışan ve farklı özelliklere sahip anten tasarımı yapılmıştır (Rajkamal ve Immadi, 2018). Meme kanserinin teşhisi için kafes bir gövdenin üstüne 6 elemanlı 2.65GHz frekansında çalışan kompakt düşük profilli giyilebilir dikdörtgen dizi anten tasarlanmıştır (AlShehhi, 2018). Meme kanserinin tespiti için giyilebilir geniş bantlı (1.6 GHz - 11.2 GHz) mikroşerit anten tasarlanmıştır (Alsharif ve Kurnaz, 2018).

İnsan vücudundaki her organa ait bir elektriksel özellik mevcut olup bu özellikler frekansla değişim göstermektedir. Herhangi bir organın elektriksel modeli belirlenirken, çalışma frekansına bağlı olarak organın iletkenlik $(\sigma)$ elektriksel ve ( $(\varepsilon r)$ manyetik geçirgenlik $(\mu \mathrm{r})$ değerleri belirlenmelidir. Şekil 1'de insan vücudundaki bazı organların iletkenlik değerlerinin $10 \mathrm{MHz}-10 \mathrm{GHz}$ frekans bandındaki değişimi verilmiştir (Chen ve dig., 2017). İnsan vücudunda tümörlü/kanser dokusu ile normal doku arasındaki temel ayrım elektriksel özelliklerininin farklı olmasıdır. Elektriksel özelliklerinin farklı olmasına bağlı olarak bu dokular üzerine gönderilen elektromanyetik dalgaların yansımaları da farklı olmaktadır. Bu elektriksel özellik farkını kullanmak mikrodalga görüntüleme sistemlerinin temelini oluşturmaktadır. Mikrodalga görüntüleme sistemlerinde elektromanyetik dalgayı doku üzerine göndermek için verici anten, doku üzerinden yansıyan bileşenlerini toplamak için de alıcı anten kullanılır. Şekil 1'den de görüldüğü gibi akciğer, beyin, karaciğer, böbrek gibi organlarda bulunan tümörleri tespit etmek için kullanılacak antenlerin çalışma bant genişliği yaklaşık 1 $\mathrm{GHz}$ ile $10 \mathrm{GHz}$ arasında olmalıdır. 


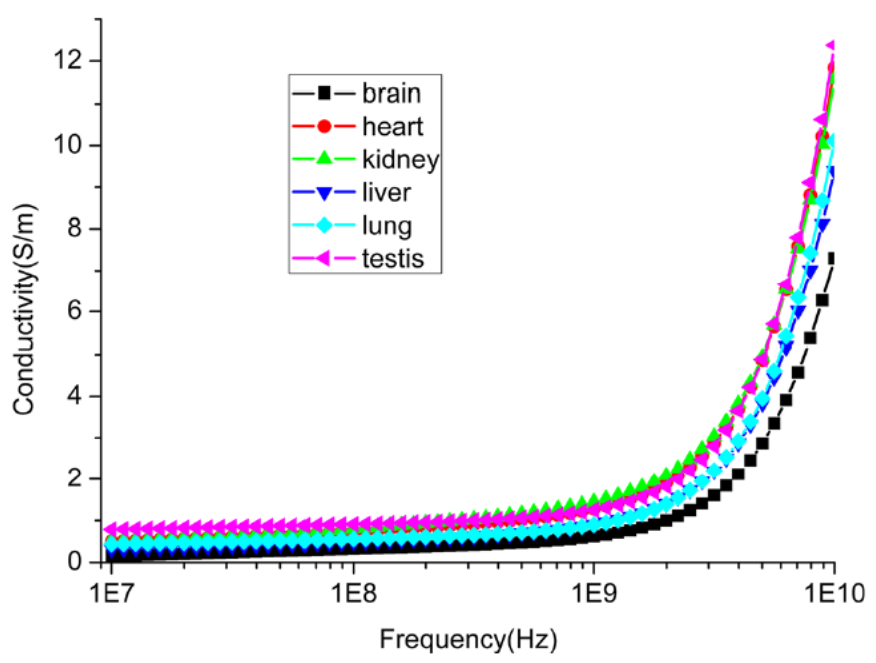

Şekil 1. İnsan vücudundaki bazı organların iletkenlik değerinin frekansla değişimi

Mikrodalga görüntüleme sistemlerinde, vücutta bulunan kanserli dokuyu/hücreyi mikroşerit anten kullanarak tespit etmek için en yaygın olarak kullanılan yöntem; verici anten ile gönderilen sinyalin vücudun ilgili bölgesindeki yansımalarını alıcı anten kullanarak kaydetmek ve işaret işleme yöntemleri ile analiz etmektir. Normal doku ile tümörlü dokunun elektriksel özellikleri farklı olduğundan gönderilen sinyalin bu dokulardan yansıyarak alıcıya ulaşan sinyal değerlerinin genlikleri de farklı olacaktır. Bu farklı yansıma değerleri kaydedilerek ve değişimleri incelenerek vücudun ilgilenilen bölgesinde bir tümör dokusunun var olup olmadığı bilgisine ulaşılabilir. Bu çalışmada akciğer, beyin, karaciğer, böbrek gibi organlarda bulunan tümörleri tespit etmek için kullanılmak üzere 1 $\mathrm{GHz}$ ile $10 \mathrm{GHz}$ arasında çalışabilen küçük boyutlu bir mikroşerit anten tasarlanmıştır. Antenin pratikte kullanılması için insanın göğüs kısmına yerleştirilmesi gerekmektedir. Bu yüzden kişiyi/hastayı rahatsız etmemesi için, antenin iki katmanı iletken bakır banttan, yalıtkan kısmı ise PF-4 (köpük) malzemeden olmak üzere giyilebilir/esneyebilir malzemeden yapılmıştır. Ayrıca antenin boyutları insana herhangi bir rahatsızlık vermemek adına insan vücudunun herhangi bir noktası için büyük olmayacak şekilde seçilmiş̧ir.

Makalenin geri kalanı şu şekilde organize edilmiştir: II. Bölümde mikroşerit antenlerin tasarımında kullanılan temel eşitlikler ve tasarlanacak olan antenin fiziksel özellikleri sunulurken, III. Bölümde tasarlanan ve gerçeklenen anten için yapılan değerlendirmeler verilmiş̧ir. Makale V. Bölüm olan Sonuçlar bölümü ile sonlandırılmıştır.

\section{Materyal ve Metot}

Mikroşerit anten tasarımında ilk olarak çalışma frekansı $\left(f_{\mathrm{r}}\right)$, elektriksel geçirgenlik katsayısı $\left(\varepsilon_{\mathrm{r}}\right)$ ve dielektrik malzemenin yüksekliği (h) değerleri belirlenir. Sonrasında bu değerler (1), (2) ve (3) eşitliklerinde yerleştirilerek yama (patch) kısmın genişliği $(\mathrm{W})$, yalıtkanın geçirgenlik katsayısının etkin değeri $\left(\varepsilon_{\text {eff }}\right)$, saçaklanma etkisiyle yama boyundaki değişim $(\Delta \mathrm{L})$ hesaplanır (Balanis, 2005).

$$
\begin{aligned}
W & =\frac{c}{2 f_{\mathrm{r}}} \sqrt{\frac{2}{\varepsilon_{\mathrm{r}}+1}} \\
\varepsilon_{\text {eff }} & =\frac{\varepsilon_{\mathrm{r}}+1}{2}+\frac{\varepsilon_{\mathrm{r}}-1}{2}\left[1+12 \frac{\mathrm{h}}{\mathrm{W}}\right]^{-\frac{1}{2}} \\
\Delta \mathrm{L} & =0.412 \mathrm{~h} \frac{\left(\varepsilon_{\text {eff }}+0.3\right)\left(\frac{\mathrm{W}}{\mathrm{h}}+0.264\right)}{\left(\varepsilon_{\text {eff }}-0.258\right)\left(\frac{\mathrm{W}}{\mathrm{h}}+0.8\right)}
\end{aligned}
$$

Saçaklanma etkisiyle yamanın elektriksel boyu Şekil 2'de gösterildiği gibi bir artış göstermektedir. Yamanın boyutları her iki kenardan da $\Delta$ L uzunluğunda genişlediği için yamanın etkin uzunluğu (4) eşitliğinde verildiği gibi ifade edilebilir (Balanis, 2005).

$$
\begin{aligned}
& \mathrm{L}_{\text {eff }}=\mathrm{L}+2 \Delta \mathrm{L} \\
& \mathrm{L}_{\text {eff }}=\frac{\mathrm{c}}{2 \mathrm{f}_{\mathrm{r}} \sqrt{\varepsilon_{\mathrm{eff}}}}
\end{aligned}
$$




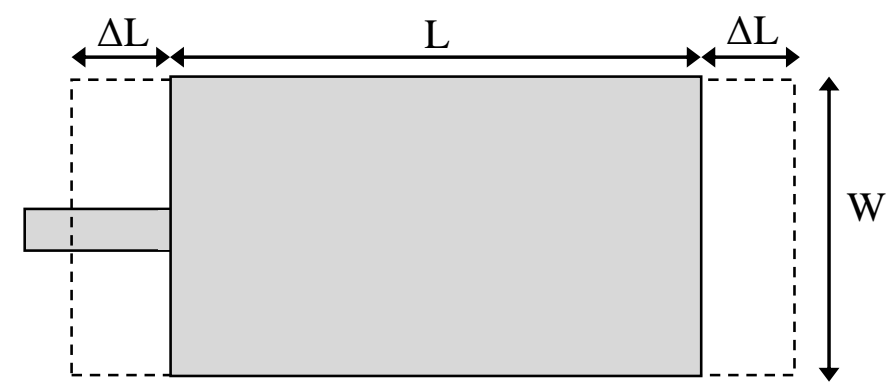

Şekil 2. Antenin yama kısmının üstten görünüşü

Dikdörtgen mikroşerit antenin üç boyutlu detaylı görünümü ve ilgili adlandırmalar Şekil 3'de detaylı bir şekilde verilmiştir.

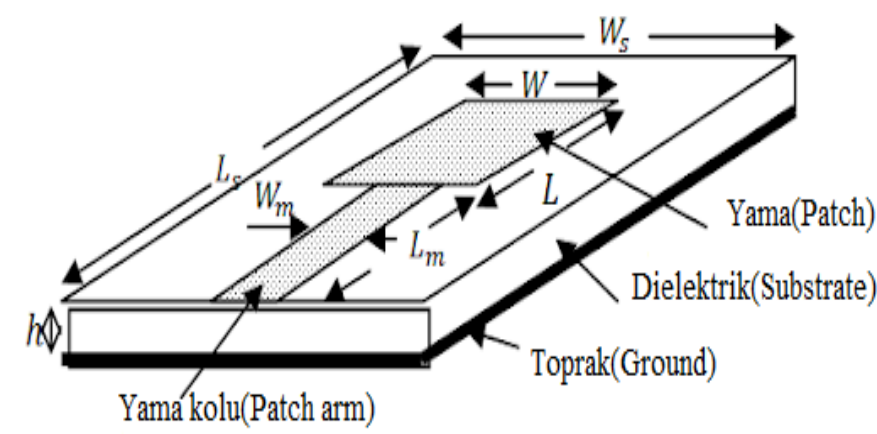

Şekil 3. Dikdörtgen mikroşerit antenin üç boyutlu görünümü.

Dielektrik tabakanın kalınlığıyla ile serbet uzaydaki dalga boyu ( $\left.\lambda_{0}\right)$ arasındaki ilişki (6) eşitliği ile ifade edilir (Balanis, 2005).

$$
0.003 \lambda_{0} \leq h \leq 0.05 \lambda_{0}
$$

Dielektrik tabakanın genişliği ve uzunluğuyla yamanın genişliği ve uzunluğu arasındaki ilişkiler (7) ve (8) eşitliklerinde verildiği gibidir (Balanis, 2005).

$$
\begin{gathered}
\mathrm{W}_{\mathrm{s}}=\mathrm{W}+6 \mathrm{~h} \\
\mathrm{~L}_{\mathrm{s}}=\mathrm{L}+6 \mathrm{~h}
\end{gathered}
$$

Yama kolunun genişliği (9) eşitliği ile ifade edilir (Balanis, 2005).

$$
\mathrm{W}_{\mathrm{m}}=\frac{7.48 \mathrm{~h}}{\mathrm{e}^{\left(\mathrm{z}_{0} \frac{\sqrt{\varepsilon_{\mathrm{r}}+1.41}}{87}\right)}}-1.25 \mathrm{t}
$$

Burada t iletken malzemenin (yama ve toprak) kalınlı̆ı̆ını göstermektedir.

Yama kolunun uzunluğu ise (10) eşitliğinde verildiği gibidir (Balanis, 2005).

$$
\mathrm{L}_{\mathrm{m}}=\left(\frac{\mathrm{c}}{\mathrm{f}}\right) /(4 \sqrt{\mathrm{K}})
$$

Burada K değeri (11), (12) ve (13) eşitliklerinde verilen katsayılar kullanılarak (14) eşitliğindeki gibi hesaplanır (Balanis, 2005).

$$
G=\sqrt{4500\left(\varepsilon_{\mathrm{r}}\right)^{2}\left(\frac{\mathrm{L}}{\mathrm{W}}\right)^{2} /\left(\varepsilon_{\mathrm{r}}-1\right)}
$$




$$
\begin{gathered}
\mathrm{a}_{3}=\mathrm{e}^{\left(\mathrm{G} \sqrt{\varepsilon_{\mathrm{r}}} / 60\right)}, \mathrm{p}=4 \mathrm{ha}_{3}, \quad \mathrm{q}=32 \mathrm{~h}^{2} \\
\mathrm{~W}_{\mathrm{t}}=-\left(\frac{\mathrm{p}}{2}\right)-\sqrt{\left(\left(\frac{\mathrm{p}}{2}\right)^{2}-\mathrm{q}\right)} \\
\mathrm{K}=\left(\frac{\varepsilon_{\mathrm{r}}+1}{2}\right)+\left(\left(\frac{\varepsilon_{\mathrm{r}}-1}{2}\right) \times\left(\frac{1}{\sqrt{\left(1+\left(\frac{\mathrm{h}}{\mathrm{W}_{\mathrm{t}}}\right)\right)}}\right)\right)
\end{gathered}
$$

Anten değerlendirmelerinde en çok dikkat edilen parametreler yansıma katsayısı (reflection coefficient), gerilim duran dalga oranı (voltage standing wave ratio, VSWR) ve geri dönüşüm kaybıdır (return loss, RL). Bir anten için yansıma katsayısı ifadesi (15) eşitliğinde verildiği gibidir. $S_{11}$ antenin çalışma frekans aralığını ifade etmek için kullanılan temel parametrelerdendir.

$$
\Gamma=\mathrm{S}_{11}=\frac{\mathrm{Z}_{\mathrm{L}}-\mathrm{Z}_{0}}{\mathrm{Z}_{\mathrm{L}}+\mathrm{Z}_{0}}
$$

Burada $Z_{L}$ yük direncini, $Z_{0}$ ise antenin karakteristik empesansını göstermektedir.

Gerilim duran daga oranı (11), geri dönüşüm kaybı ise (16) eşitliklerinde verildiği gibidir.

$$
\operatorname{VSWR}=\frac{1+|\Gamma|}{1-|\Gamma|}
$$

Geri dönüşüm kaybı (Return Loss) ifadesi ise (17) eşitliğinde verildiği gibi hesaplanır.

$$
\mathrm{RL}(\mathrm{dB})=-20 \log |\Gamma|
$$

CST (Computer Simulation Technology) Microwave Studio programı yardımıla tasarlanan dikdörtgen mikroşerit antene ait görsel Şekil 4'de verilmiştir. Tasarlanan dikdörtgen mikroşerit anten üç temel parçadan oluşmaktadır. Bunlar; en üstte yama, altında yalıtkan (dielektrik, substrate) malzeme ve en alt kısımda da toprak (ground) kısmıdır. Bu üç parçadan ikisi (yama ve toprak) iletken bakır banttan oluşmaktadır. Dielektrik kısım ise normal PF-4’ten oluşmuştur. Pratik olarak gerçekleştirilen antenin her üç parçasının ebatları Şekil 5'de detaylı bir şekilde verilmiştir.

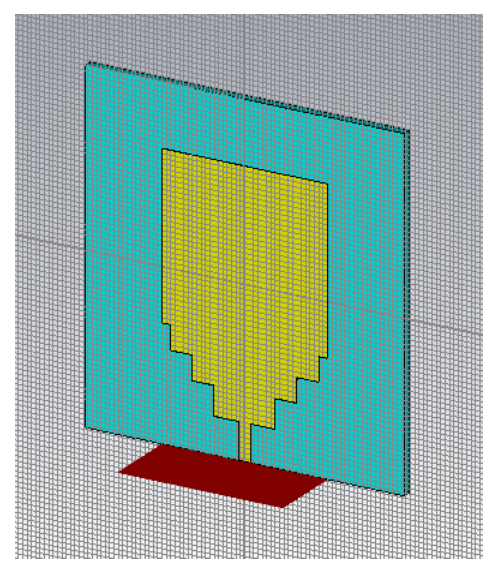

Şekil 4. CST programıyla oluşturulan dikdörtgen mikroşerit antenin görüntüsü 

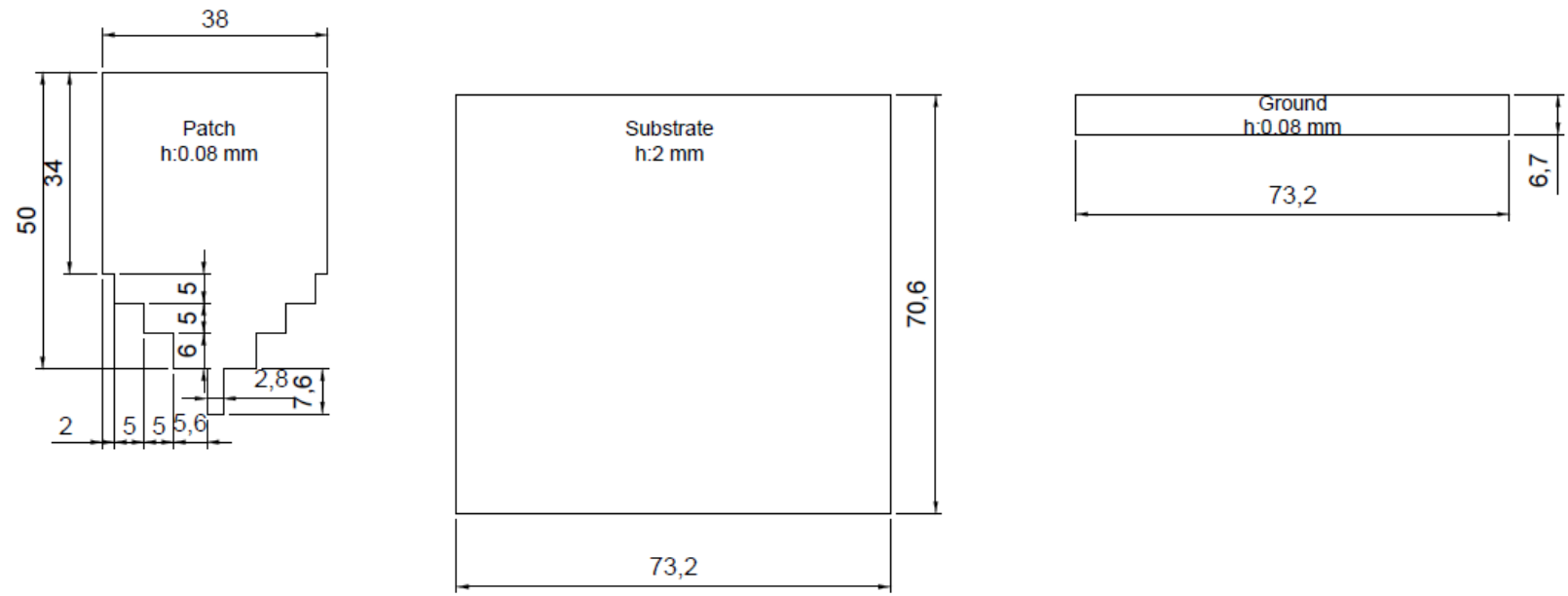

Şekil 5. Tasarlanan dikdörtgen mikroşerit antenin boyutları

\section{Araştırma Sonuçları ve Tartışma}

CST programı ile oluşturulan antenin gerçeklenmesi (fabrication) yapılmış ve SMA konnektör anten beslemesi için kullanılmıştır. Gerçeklenen antenin ön ve arka kısmına ait görüntüler Şekil 6’da verilmiştir.
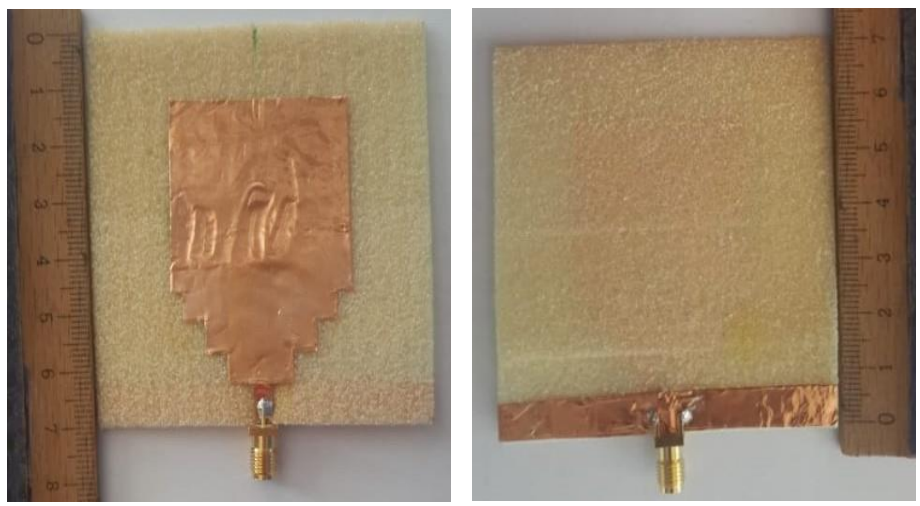

Şekil 6. Gerçeklenen antenin önden ve arkadan görüntüsü

Gerçeklenen antenin $\mathrm{S}_{11}$ parametresi Keysight marka N5221B model (13.5 GHz’e kadar ölçüm özellikli) vektör network analizörü (vector network analyzer, VNA), 1şıma paterni ise yankısız oda (anechoic chamber) koşullarında ölçülmüştür. $S_{11}$ ölçümleri için örnek foto Şekil 7.a'da yankısız oda için ise Şekil 7.b'de gösterilmiştir.
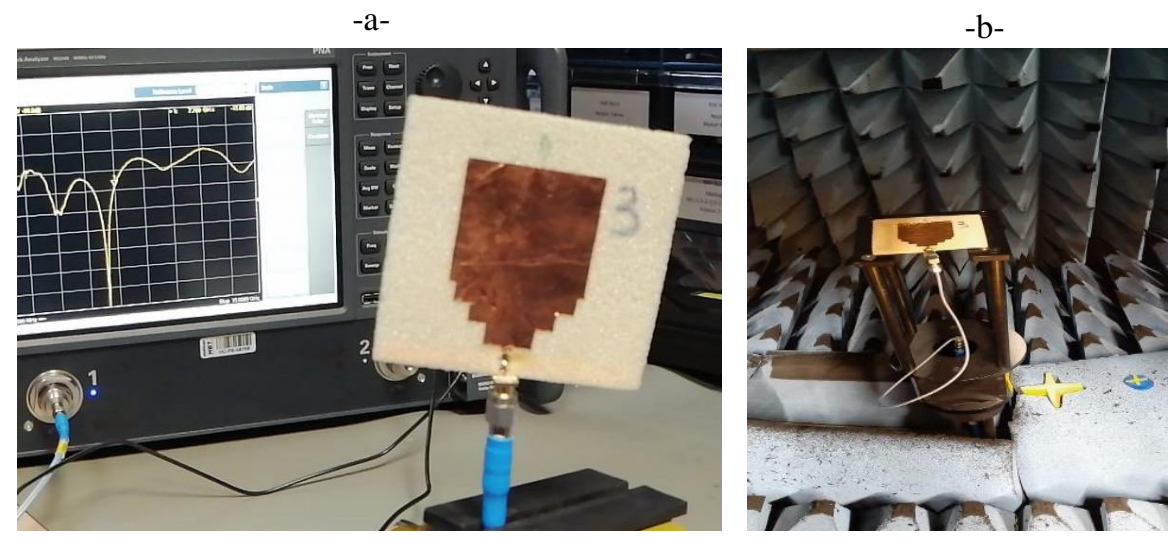

Şekil 7. Greçeklenen antene ait a) VNA b) Yankısız oda ölçümlerine ait görseller 
CST programı kullanılarak tasarlanan antenin $\mathrm{S}_{11}$ parametresinin CST ve VNA sonuçları Şekil 8'de verilmiştir. Şekilden de görüldüğü gibi tasarlanan anten ile gerçeklenen antenin $S_{11}$ parametresinin birbirine oldukça yakın olduğu görülmektedir. $S_{11}$ için -10 $\mathrm{dB}$ altı frekans aralığı referans alındığında CST ortamında tasarlanan antenin frekans bandı yaklaşık $6.82 \mathrm{GHz}$ dir $(1.71 \mathrm{GHz}-8.53$ $\mathrm{GHz}$ ). Bu değer gerçeklenen mikroşertit anten için ise $6.75 \mathrm{GHz}$ dir (1.6 GHz- $8.35 \mathrm{GHz})$. Mikroşerit antenlerin çok dar bantlı oldukları $(0.1 \mathrm{GHz})$ düşünüldüğünde çalışma kapsamında tasarlanan antenin oldukça geniş bir frekans aralığında kullanılabilir olduğu görülmektedir.

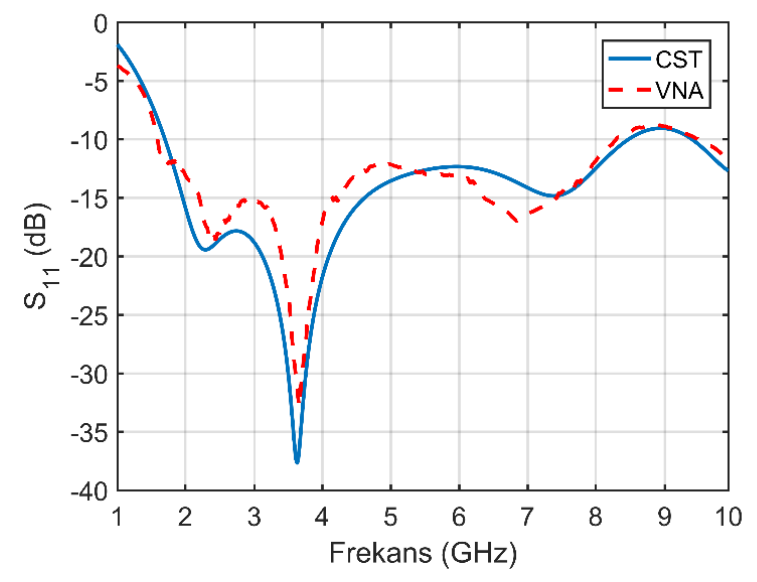

Şekil 8. Tasarlanan (CST) ve gerçeklenen (VNA) antenler için $\mathrm{S}_{11}$ değerleri

Tasarlanan antenin kazanç grafiği Şekil 9'da verilmiştir. Normalde mikroşerit antenlerde kazanç, antenlerin küçük boyutlarından dolayı oldukça küçüktür. Ancak tasarlanan antenin kazancı Şekil 9'dan da görüldüğü gibi 5.31 dB gibi yüksek bir değere sahiptir.

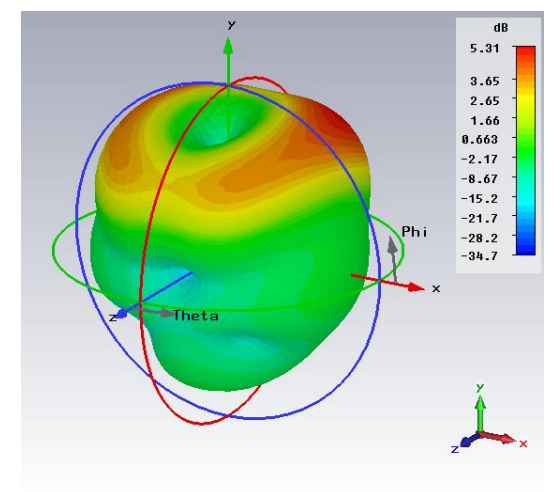

Şekil 9. Tasarlanan antenin açı değerine bağlı (phi, theta) kazanç değişimi

Kazancın kutupsal değişimi anten değerlendirmelerinde büyük bir öneme sahiptir. Bu değişime bakılarak antenin $3 \mathrm{~dB}$ açıklığıyla, kazancın açıyla nasıl bir değişim gösterdiği kolaylıkla analiz edilebilir. Antenin iki boyutlu (2D) değişimi antenden gönderilen işaretin hangi açılarda yoğunlaştığını, antenin yönlülüğünü, alıcı anteni hangi noktaya yerleştirebileceğimizle ilgili bilgiler vermektedir. Şekil 10'da verildiği gibi antenin yönlülüğünün çok iyi olduğu, gücün yaklaşık olarak her yöne benzer yayıldığı görülmektedir. 


\section{Avrupa Bilim ve Teknoloji Dergisi}

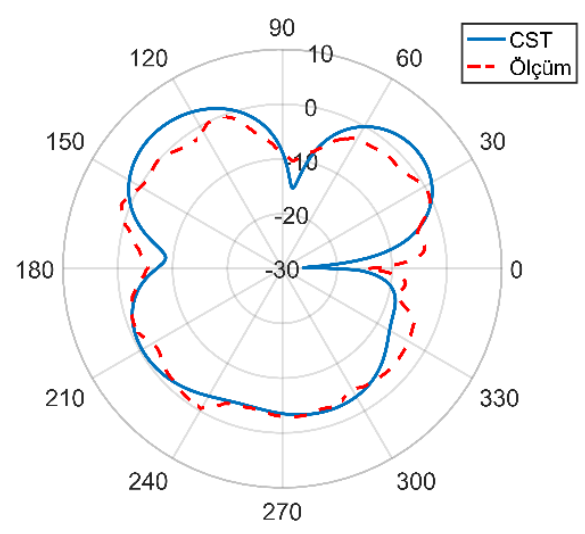

Şekil 10. Kazancın kutupsal değişimi

Antenin iki boyutlu değişimi antenden gönderilen işaretin hangi açılarda yoğunlaştığını, antenin yönlülüğünü, alıcı anteni hangi noktaya yerleştirebileceği ile ilgili blgiler vermektedir. Tasarlanan antenin iki boyutlu kazanç değişimi Şekil 11'de verilmiştir. Şekilden de görüldüğü gibi antenin yönlülüğünün çok iyi olduğunu gücün çok dar bir alan içerisinde dağıldığı söylenebilir.
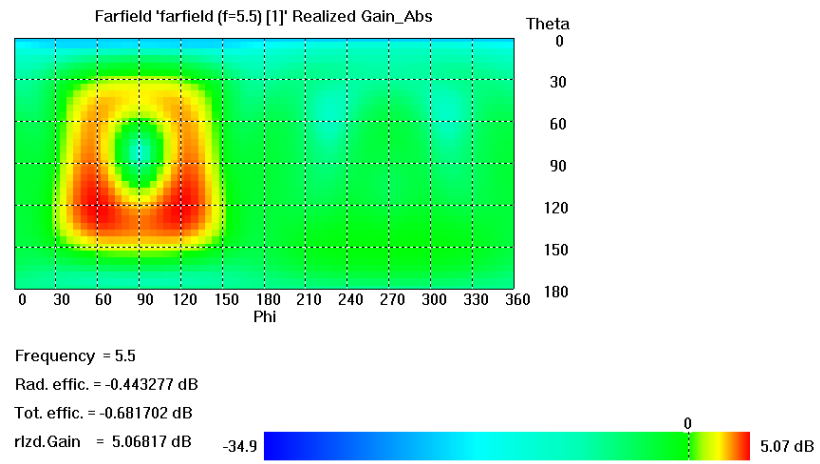

Şekil 11. Anten kazancının iki boyutlu değişimi

Elektrik alanın açılara bağlı değişimi alanın nerelerde yoğunlaştığı, değeri, alıcı anteni konumlandırma mesafesi ile ilgili bilgiler vermektedir. Şekil 12'de tasarlanan antenin etrafında oluşan elektrik alanın açıya bağlı değişimi verilmiştir. Anten etrafında elekrik alan dağılımının oldukça iyi olduğu bu değerlerin açıyla değişiminden görülebilmektedir. Elektrik alan değişimine bakılarak, pratikte bu sistemin uygulandığı kişinin maruz kaldığı elektromanyetik alanın dünya sağlık örgütünün belirlediği limit değerlerden (1 GHz $10 \mathrm{GHz}$ için en yüksek değer $35.7 \mathrm{dBV} / \mathrm{m}$ 'dir (ICNIRP, 1998)) daha küçük olacak şekilde verici antenin konumlandırabileceği görülmektedir.

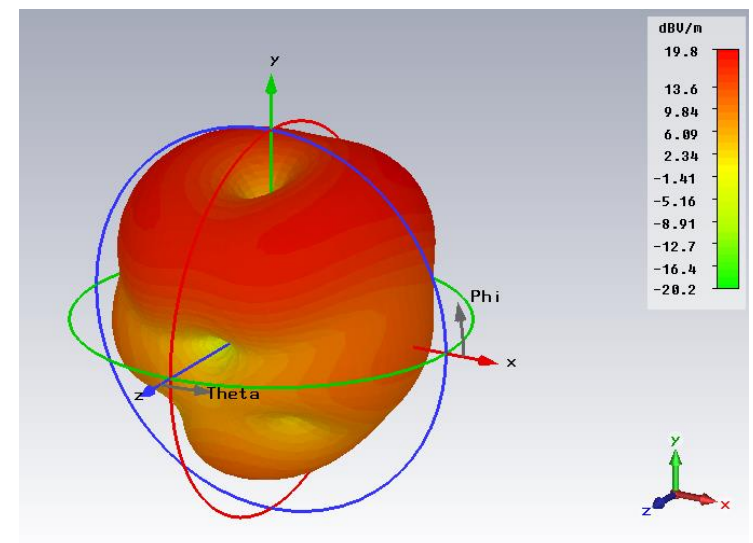

Şekil 12. Antenin elektrik alanının açıya (phi, theta) bağlı değişimi 


\section{Sonuç}

Bu çalışmada akciğer, beyin, karaciğer, böbrek gibi organlarda bulunan tümörleri tespit etmek için hem alıcı hemde verici olarak mikrodalga görüntüleme sistemlelerinde kullanılabilecek giyilebilir dikdörtgen kesitli bir mikroşerit anten tasarlanmıştır. İlk önce CST ortamında benzetimsel olarak tasarlanan anten sonrasında gerçeklenmiştir. VNA ve yankısız oda koşullarında analizleri yapılan antenin CST ortamında tasarlanan antene ait parametrelerin birbirlerine çok yakın olduğu görülmüştür. Tasarlanan antenin kazancı, klasik mikroşerit antenlere göre oldukça yüksektir $(5.31 \mathrm{~dB})$. Tasarlanan antenin çalışma frekans aralığına bakıldığında gerek teorik gerekse gerçek anten değeri için $6.8 \mathrm{GHz}$ civarında olduğu görülmektedir Çok dar bandlı $(0.1 \mathrm{GHz})$ klasik mikroşerit antenlerle karşılaştırıldığında bu değerlerin çok iyi olduğu görülmektedir. Antenin giyilebilir özellikte olması için dielektrik kısmı esnek bir malzeme olan PF-4 (köpük) kullanılarak gerçeklenmiştir. Böylece tasarlanan anten özellikle kanser riski yüksek olan hastaların sürekli izlemesinde rahatllkla kullanılabilir.

\section{Kaynakça}

Akalya, C.G., Nandalal, V., (2017). On-Body Adhesive Microstrip Antenna for Wearable Application. International Journal of Communications, Cilt 2, ss. 137-145.

Albairaqdar, O.H.M. (2018) Giyilebilir Uygulamalar İçin Eşit Yama Alanına (EYA) Sahip Tekstil Dielektrik Malzeme Tabanlı Mikroşerit Antenlerin 2.4, 3 ve 5.8 GHz frekanslarındaki Performansları. Yüksek Lisans Tezi, Selçuk Üniversitesi.

Alsharif, F., Kurnaz, Ç. (2018). Wearable Microstrip Patch Ultra Wide Band Antenna for Breast Cancer Detection. 41st International Conference on Telecommunications and Signal Processing, 4-6 July 2018, Athens, Greece.

AlShehhi, H., Alzarouni M., AlYammahi, N., Shubair, R., Ali N. (2018). Compact Low-Profile Wearable Antennas for Breast Cancer Detection. Technical Report, Cornell University.

Balanis, C.A., (2005). Antenna Theory: Analysis and Design: Willey-Inter Science.

Chahat, N., Zhadobov M., Sauleau, R., Ito, K. (2010). Design and Characterization of an UWB Wearable Antenna. Loughborough Antennas and Propagation Conference (LAPC), 8-9 Nov. 2010, Loughborough, UK.

Chen, B. Wang, J. Qi, H. Zhang, J. Chen, S. Wang, X. (2017). The Specific Absorption Rate of Tissues in Rats Exposed to Electromagnetic Plane Waves in the Frequency Range of $0.05-5 \mathrm{GHz}$ and SAR wb in Free-moving Rats. Australasian Physical \& Engineering Sciences in Medicine March. Cilt 40, Sayı 1, ss. 21-28.

Deschamps, G.A. (1953). Microstrip Microwave Antennas. 3rd USAF Symposium on Antennas.

GCO, (2020), Türkiye Kanser İstatistikleri, https:/gco.iarc.fr/today/data/factsheets/populations/792-turkey-fact-sheets.pdf, (Erişim tarihi 3 Ekim 2020).

Georges, B., Henri, G. (1955). Flat Aerial for Ultra High Frequencies. French Patent No. 703113.

Faria, J.V. (2015). Flexible Antennas Design and Test for Human Body Applications Scenarios. Master of thesis, Instituto Superior Tecnico Lisboa.

Howell, J.W. (1975). Microstrip antennas. IEEE Transactions Antennas Propagation. Cilt AP-23, Say1 1, ss. 90-93.

HSGM, (2020), Türkiye Kanser İstatistikleri 2016, https://hsgm.saglik.gov.tr/depo/birimler/kanserdb/istatistik/Trkiye_Kanser_statistikleri_2016.pdf, (Erişim tarihi 3 Ekim 2020).

ICNIRP, (1998). Guidelines for Limiting Exposure to Time-varying Electric, Magnetic and Electromagnetic Fields (up to 300 GHz). Health Physics. Cilt 74, Say1 4, ss.494-522.

Lakshmanan, R., Sukumaran, S. K. (2015). Flexible Ultra Wide Band Antenna for WBAN Applications. Procedia Technology. Cilt 24, ss. 880-887.

Munson, R.E. (1974). Conformal Microstrip Antennas and Microstrip Phased Arrays. IEEE Transactions Antennas Propagation, Cilt AP-22, Sayı 1, ss. 74-78.

Rajkamal, K., Immadi, G. (2018). Design and Analysis of Different Substrate Materials for UWB Antenna used for Biomedical Applications. Journal of Theoretical and Applied Information Technology. Cilt 96, Say1 7, ss. 1992-8645.

Sankaralingam, S., Gupta, B. (2010). Development of Textile Antennas For body Wearable Applications and Investigations On Their Performance under Bent Conditions. Progress in Electromagnetics research, Cilt 22, ss. 53-71.

Singh, N. Singh, A.K., Singh V. K. (2015). Design and Performance of Wearable Ultra Wide Band Textile Antenna for Medical Applications. Open Engineering, Cilt 57, Say1 5, ss.117-123.

Tuovinen, T., Berg, M., Kamya, Y, Matti, Y., Jari Iinatti, H. (2013). On the Evaluation of Biological Effects of Wearable Antennas on Contact with Dispersive Medium in Terms of SAR and Bio-Heat by Using FIT Technique Centre for Wireless Communications. International Symposium on Medical Information and Communication Technology. 6-8 March, Tokyo, Japan.

WHO, (2020). WHO report on cancer: setting priorities, investing wisely and providing care for all, https://www.who.int/publications/i/item/who-report-on-cancer-setting-priorities-investing-wisely-and-providing-care-for-all (Erişim tarihi 3 Ekim 2020).

WCRF, (2020). Worldwide cancer data Global cancer statistics for the most common cancers, https://www.wcrf.org/dietandcancer/cancer-trends/worldwide-cancer-data, (Erişim tarihi 3 Ekim 2020).

Zasowski, T., Althaus, F., Stager, M., Wittneben, A., Tröster, G. (2003). UWB for Noninvasive Wireless Body Area Networks Channel Measurements And Results. IEEE Conference on Ultra Wideband Systems and Technologies, 6-19 November, Reston, VA, USA. 